\title{
Associations of neck muscle strength and cervical spine mobility with future neck pain and disability: a prospective 16-year study
}

\author{
Juhani Multanen ${ }^{1,2^{*}}$, Arja Häkkinen ${ }^{1,2}$, Hannu Kautiainen ${ }^{3,4}$ and Jari Ylinen ${ }^{2}$
}

\begin{abstract}
Background: Neck pain has been associated with weaker neck muscle strength and decreased cervical spine range of motion. However, whether neck muscle strength or cervical spine mobility predict later neck disability has not been demonstrated. In this 16-year prospective study, we investigated whether neck muscle strength and cervical spine mobility are associated with future neck pain and related disability in women pain-free at baseline.

Methods: Maximal isometric neck muscle strength and passive range of motion (PROM) of the cervical spine of 220 women (mean age 40, standard deviation (SD) 12 years) were measured at baseline between 2000 and 2002. We conducted a postal survey 16 years later to determine whether any subjects had experienced neck pain and related disability. Linear regression analysis adjusted for age and body mass index was used to determine to what extent baseline neck strength and PROM values were associated with future neck pain and related disability assessed using the Neck Disability Index (NDI).
\end{abstract}

Results: The regression analysis Beta coefficient remained below 0.1 for all the neck strength and PROM values, indicating no association between neck pain and related disability. Of the $149(68 \%)$ responders, mean NDI was lowest $(3.3$, SD 3.8) in participants who had experienced no neck pain $(n=50)$, second lowest $(7.7$, SD 7.1) in those who had experienced occasional neck pain $(n=94)$, and highest $(19.6$, SD 22.0) in those who had experienced chronic neck pain $(n=5)$.

Conclusions: This 16-year prospective study found no evidence for an association between either neck muscle strength or mobility and the occurrence in later life of neck pain and disability. Therefore, screening healthy subjects for weaker neck muscle strength or poorer cervical spine mobility cannot be recommended for preventive purposes.

Keywords: Neck pain, Neck disability, Association, Muscle strength, Range of motion

\section{Introduction}

Neck pain is a highly prevalent condition that affects about two-thirds of the adult population at some time during the lifespan [1]. Women are affected more often than men, and it has been thought that one reason why neck pain is more common among women is that they

*Correspondence: juhani.e.multanen@jyu.fi

${ }^{1}$ Faculty of Sport and Health Sciences, University of Jyväskylä, Jyväskylä, Finland

Full list of author information is available at the end of the article have lower muscle strength than men [2]. Although maximal muscle strength is known to peak between ages 20 and 30 [3], evidence suggests that the prevalence of chronic neck pain peaks in middle-age and decreases thereafter $[4,5]$. This is a puzzling finding that merits further investigation. Even though neck pain usually resolves within days or weeks, it has a high rate of transition to a chronic or persistent problem, as it becomes chronic in $5-7 \%$ of cases $[6,7]$. The International Association for the Study of Pain (IASP) defines neck pain of more than 3 months' duration as original author(s) and the source, provide a link to the Creative Commons licence, and indicate if changes were made. The images or other third party material in this article are included in the article's Creative Commons licence, unless indicated otherwise in a credit line to the material. If material is not included in the article's Creative Commons licence and your intended use is not permitted by statutory regulation or exceeds the permitted use, you will need to obtain permission directly from the copyright holder. To view a copy of this licence, visit http://creativecommons.org/licenses/by/4.0/. The Creative Commons Public Domain Dedication waiver (http://creativeco mmons.org/publicdomain/zero/1.0/) applies to the data made available in this article, unless otherwise stated in a credit line to the data. 
chronic [8]. Neck pain has substantial effects on quality of life and work ability, and thus imposes a significant personal and socioeconomic burden [9].

To prevent neck pain requires an understanding of the predisposing factors for its development. Although little is known about the etiology of neck pain and related disability, the literature suggests that the risk for developing neck pain may be affected by different physical, psychosocial, and individual-level factors [10]. In the case of physical risk factors, research has consistently shown an association between neck pain and decreased neck muscle strength [11-16]. Further, several randomized studies have reported a decrease in neck pain as a result of neck musclestrengthening rehabilitation programs [17-20]. Similarly, patients with neck pain have shown a decreased cervical range of motion compared with persons without neck pain [11, 21-24]. Some randomized studies have also reported a decrease in neck pain and improved cervical range of motion as a result of neck muscle-strengthening rehabilitation programs $[18,25]$. However, it remains unclear whether neck pain causes weakness in neck muscles or whether weak neck muscles generate neck pain. Similarly, the relationship between decreased spinal mobility and neck pain is equivocal.

It seems reasonable to assume that naturally good neck muscle strength and range of motion are likely to be protective factors against neck pain. Although numerous studies have investigated the association between neck pain and cervical muscle strength or range of motion, few prospective cohort studies have focused on the possible prognostic value of muscle strength and spine mobility for the later development of neck pain. The results of the few existing studies suggest that spine mobility has no predictive value for the later occurrence of neck pain in originally painfree subjects, while the results for muscle strength have been conflicting [26, 27]. Thus, further evidence is needed to clarify whether neck muscle strength and cervical spine mobility could predict future neck pain. In addition, the previous studies have not taken chronic neck pain or related disability into consideration. The Neck Disability Index (NDI), which is the most commonly used self-report instrument for evaluating neck pain status, provides information not only about experiences of pain but also about a subject's functional capacity [28]. Hence, in the present study we explored prospectively whether neck muscle strength and mobility of the cervical spine were associated with functional capacity in later life measured using neck pain and the NDI among subjects who were pain-free at the time of the baseline measurements.

\section{Methods}

\section{Study design}

This study was a 16-year prospective survey to assess the possible association of neck muscle strength and mobility with the development of neck pain and related disability. The Ethics Committee of the Central Finland Health Care District approved the study plan (protocol approval number 41/2000) which was designed in accordance with the guidelines of the Declaration of Helsinki. All participants gave their written informed consent prior to enrollment.

\section{Subjects}

The original study group comprised female volunteers recruited through advertisements targeted to the personnel of the largest employers in the City of Jyväskylä, Finland. The study focused on females owing to the higher prevalence of neck pain in females [29]. The 241 subjects who indicated interest in the study were sent a screening questionnaire to assess their eligibility to participate. These individuals worked either for the municipality or at the local hospital or for various industrial facilities employing both blue- and white-collar workers, or they were students. The screening questionnaire included items on health status, occupation, and engagement in competitive sports. Inclusion criteria were being female, healthy, and aged between 20 and 59 years (this wide age range was purposely used to establish reference values for cervical spine mobility and muscle strength in working-age females). Exclusion criteria were: neck and shoulder pain experienced within the previous 6 months, previous or current injuries or other disorders of the neck or shoulder region, rheumatoid arthritis, fibromyalgia, severe depression or mental disorder, or active participation in competitive sport. We excluded 18 of the 241 volunteers owing to neck or shoulder symptoms and 3 owing to missing information, thus yielding a sample of 220 healthy females for the study.

The participants completed a questionnaire on their health status, occupation, level of physical workload, and time spent on leisure-time physical activity. The visual analog scale (VAS, $0-100 \mathrm{~mm}$ ) was used to check that they had experienced no neck pain during the week preceding the baseline measurements.

\section{Baseline measurements}

The baseline measurements, including body height and mass, were performed between November 2000 and October 2002 for all participants by the same physiotherapist. Maximal isometric strength of the flexor, extensor, and rotator muscles of the cervical spine was measured with a specially designed neck strength measurement system (NSMS; Kuntoväline Ltd., Helsinki, Finland). The wall-attached system has two adjustable, 
rigid plates to stabilize the subject's trunk. The subject's chest and waist were tightly fastened to these plates with wide straps at the level of the iliac crest and above the inferior angle of the scapula. The subject was seated with hips and knees at $90^{\circ}$ of flexion. The head was held in an upright neutral position. During the testing of flexion force, the subject was seated directly facing the device with a bar equipped with a force cell in contact with her forehead. During the recording of extension force, the subject turned $180^{\circ}$, so that her back ended up facing the device and the force cell was in contact with her occiput. Muscle strength for cervical spine rotation was measured with an overhead module consisting of four pads that were attached to both sides of the subject's head. The subject's head was secured in a neutral position by tightening all four pads at the same time. In addition, the subject's chin was supported with a bar to avoid head movements. The axis of rotation was adjusted by centering the overhead module parallel to a vertical line with external auditory canals. The force cell was attached to the axis of the overhead module.

Neck strength was measured first for rotation, followed by flexion and extension. Two warm-up trials were performed, followed by three maximum-effort trials in each direction. The highest result in each direction was used in the analyses. The results of the baseline measurements for the original 220 subjects have been presented in detail elsewhere [30]. These strength measurements have been found to have good intratester reliability with intraclass correlation coefficient (ICC) values ranging from 0.87 to 0.96 , depending on the direction tested [30].

Passive range of motion (PROM) of the cervical spine using a cervical measurement system (CMS; Kuntoväline Ltd., Helsinki, Finland) was measured in all three planes of motion: lateral flexion (frontal plane), axial rotation (horizontal plane) to both the right and left sides, and flexion-extension (sagittal plane). The CMS includes two gravity goniometers, a compass goniometer, and two fluid levels attached to a plastic frame. Movement in the different planes is shown by the goniometers and compass in increments of $2^{\circ}$. The intra-rater reliability of this measure has been found to be good, with ICC values ranging from 0.79 to 0.92 [31]. In their original study, Salo and colleagues (2009) chose to assess age-related changes and establish reference values for passive range of motion of the cervical spine in healthy working-age women, as no prior studies had reported reference values for this parameter. The results of the baseline PROM measurements for the original study group of 220 subjects have been reported in detail elsewhere [31].

\section{Postal survey 16 years after baseline measurements}

We mailed a questionnaire package to the participants 16 years after the baseline measurements. They were asked whether they had experienced no neck pain at all, or neck pain occasionally for short periods of time or continuously for at least 3 months (i.e., chronic pain) since the baseline measurements. Items on illnesses, accidents, and surgical procedures, and visits to health care professionals, treatments, and medication due to neck pain were also included. We also asked the subjects about their overall perceived health, cigarette smoking, body mass and height, time spent on leisuretime physical activity, occupation, and level of physical workload. Participants also completed the Finnish validated version of the Neck Disability Index (NDI) [32], originally reported by Vernon and Mior [33], which is a functional status questionnaire containing 10 items asking about pain, personal care, lifting, reading, headaches, concentration, work, driving, sleeping and recreation. Each item is scored on a 0 to 5 rating scale, yielding a possible total score of 50 . We multiplied the participants' score by two to obtain percentage scores, as instructed by Fairbank et al. [34]. A score of $0 \%$ indicates no activity limitations and a score of $100 \%$ indicates complete activity limitation [33]. The NDI has been found to have good reliability and validity in individuals with neck pain [28]. The minimally clinically important change reported by patients was $5-10$ points on a scale of $0-50(10-20 \%)$ [35].

\section{Statistical methods}

We present descriptive characteristics using means and standard deviations (SD) or counts with percentages, and frequency distribution. The normality of variables was evaluated graphically and with the Shapiro-Wilk W test. The participants were divided into two groups according to the incidence of neck pain. We compared the groups using independent samples t-test and analysis of co-variance. For the primary outcomes between-group differences are given in mean with their $95 \%$ confidence intervals. We set the $\alpha$ level at $\leq 0.05$ for all tests. We used multiple linear regression analyses to evaluate the association between the NDI and baseline neck strength and PROM values using adjusted (age and body mass index) standardized regression coefficients (Beta). The Beta value is a measure of how strongly each variable influences the criterion (dependent) variable. Beta is measured in units of standard deviation. Cohen's standard for Beta values above $0.10,0.30$ and 0.50 represent small, moderate and large relationships, respectively [36]. We analyzed the data using the STATA 14.1 statistical software package (StataCorp, College Station, TX). 


\section{Results}

Of the 220 subjects originally recruited for the study, 149 (68\%) returned the 16-year follow-up questionnaire. Participants' characteristics and neck muscle strength and cervical spine PROM values are shown in Table 1. Of these 149 subjects, 50 (34\%) reported that they had not experienced neck pain at all (hereafter No pain group), 94 (63\%) reported occasional neck pain (Occasional group), and 5 (3\%) continuous neck pain for at least 3 months (Chronic group) during the past 16 years. The three groups were similar in all participant characteristics $(p=0.21$ to 0.87$)$.

Over the previous 16 years, six subjects from the Occasional group reported neck injuries: two collisions and one a whip-lash injury after a car wreck, two workplace head injuries, and one a wakeboard fall. Clavicle fractures were reported by two subjects in the Chronic group, one of whom reported sustained fracture-related shoulder and neck pain. A total of 32 medical visits, 27 from the Occasional group and five from the Chronic group, were made due to neck pain, of which nine were further investigated with different diagnostic imaging modalities. One subject in the No pain group reported surgery to remove lymph nodes from the neck area as part of treatment for salivary gland cancer, and one subject from the Occasional group reported a thyroidectomy.

Twenty-six subjects in the Occasional group and five subjects in the Chronic group reported receiving treatments for neck pain over a 16-year period. The most commonly-used treatment modalities were massage (26

Table 1 Current clinical characteristics, baseline neck muscle strength and cervical spine range of motion of the females $(N=149)$, who returned the questionnaire at the 16-year follow-up

\begin{tabular}{ll}
\hline Variable & Value \\
\hline Age, years, mean (SD) & $57.3(11.4)$ \\
Height, cm, mean (SD) & $165(6)$ \\
Body mass, kg, mean (SD) & $69.7(12.0)$ \\
Body mass index, kg/m², mean (SD) & $25.4(4.0)$ \\
Smoker, n (\%) & $15(10)$ \\
Retired, n (\%) & $57(38)$ \\
Leisure time physical activity, h/week, mean (SD) & $6.1(4.3)$ \\
Strength & \\
$\quad$ Extension, N, mean (SD) & $192(30)$ \\
$\quad$ Flexion, N, mean (SD) & $74(19)$ \\
$\quad$ Rotation, Nm, mean (SD) & $7.9(2.1)$ \\
Range of motion & $166(18)$ \\
$\quad$ Sagittal, ${ }^{\circ}$, mean (SD) & $191(19)$ \\
$\quad$ Horizontal, ${ }^{\circ}$, mean (SD) & $89(15)$ \\
$\quad$ Frontal, ${ }^{\circ}$, mean (SD)
\end{tabular}

subjects), exercise therapy (12 subjects), thermo- and cryotherapy (six subjects), acupuncture (five subjects), and cervical spine mobilization (four subjects). Twentythree subjects in the Occasional group and two subjects in the Chronic group reported taking painkillers for neck pain during the last 12 months. They had taken painkillers for an average of 19 (SD 41, range 2 to 200) days within the past year.

Mean NDI was lowest (3.3, SD 3.8, range 0 to 16) in the No pain group, second lowest (7.7, SD 7.1, range 0 to 38) in the Occasional group and highest (19.6, SD 22.0, range 2 to 58) in the Chronic group. The Chronic group had a significantly higher NDI than the No pain group (mean difference $16.3,95 \% \mathrm{CI}, 8.4$ to 24.2 ) or Occasional group (11.9, 95\% CI, 4.2 to 19.7$)$. The NDI was also significantly higher in the Occasional group than in No pain group (4.3, 95\% CI, 1.4 to 7.3). The distribution of NDI indices for the No pain, Occasional and Chronic subjects is shown in Fig. 1.

Since the Chronic group, which contained only 5 subjects, was too small to be included in any statistical test, the Chronic group data were pooled with the Occasional group data. Before pooling, it was ensured that the Chronic group did not differ from the Occasional group in any of the clinical characteristics $(p=0.20$ to 0.83$)$ or muscle strength $(p=0.22$ to 0.99$)$ or PROM values $(p=0.27$ to 0.54$)$. The pooled group is referred to hereafter as the Pain group. The No pain $(N=50)$ and Pain $(N=99)$ groups differed in age (mean 61.0, SD 10.9 years in the No pain and 55.5, SD 11.3 years in the Pain group, mean difference 5.5 years, $95 \% \mathrm{CI}, 1.7$ to 9.3 ). The Pain group had a significantly higher NDI than the No Pain group (mean 8.3, SD 8.7 in the Pain group and 3.3, SD 3.8 in the No Pain group, mean difference $4.9,95 \% \mathrm{CI}$, 2.4 to 7.5$)$.

The analyses for the whole group $(n=149)$ revealed that none of the isometric neck strength measures in extension, flexion, or rotation were associated with neck disability. The $\beta$ value for each of the independent predictors remained below -0.1 (small) (Fig. 2). Similarly, none of the measures of passive mobility of the cervical spine in the sagittal, horizontal, or frontal planes were associated with neck disability, as all three $\beta$ values were below -0.1 (Fig. 2).

The mean $(95 \% \mathrm{CI})$ maximal extension strength, flexion strength, and rotation strength values were 198 (190 to 205) N, 74 (69 to 79) N, and 8.3 (7.7 to 8.9$) \mathrm{Nm}$, respectively, in the No pain group and 190 (183 to 196) N, 74 (70 to 78 ) $\mathrm{N}$, and 7.8 (7.4 to 8.2$) \mathrm{Nm}$, respectively, in the Pain group (Fig. 3). No statistically significant differences were observed between the two groups in maximal extension strength $(p=0.19)$, flexion strength $(p=0.63)$, rotation strength $(p=0.18)$ or combined maximal strength 


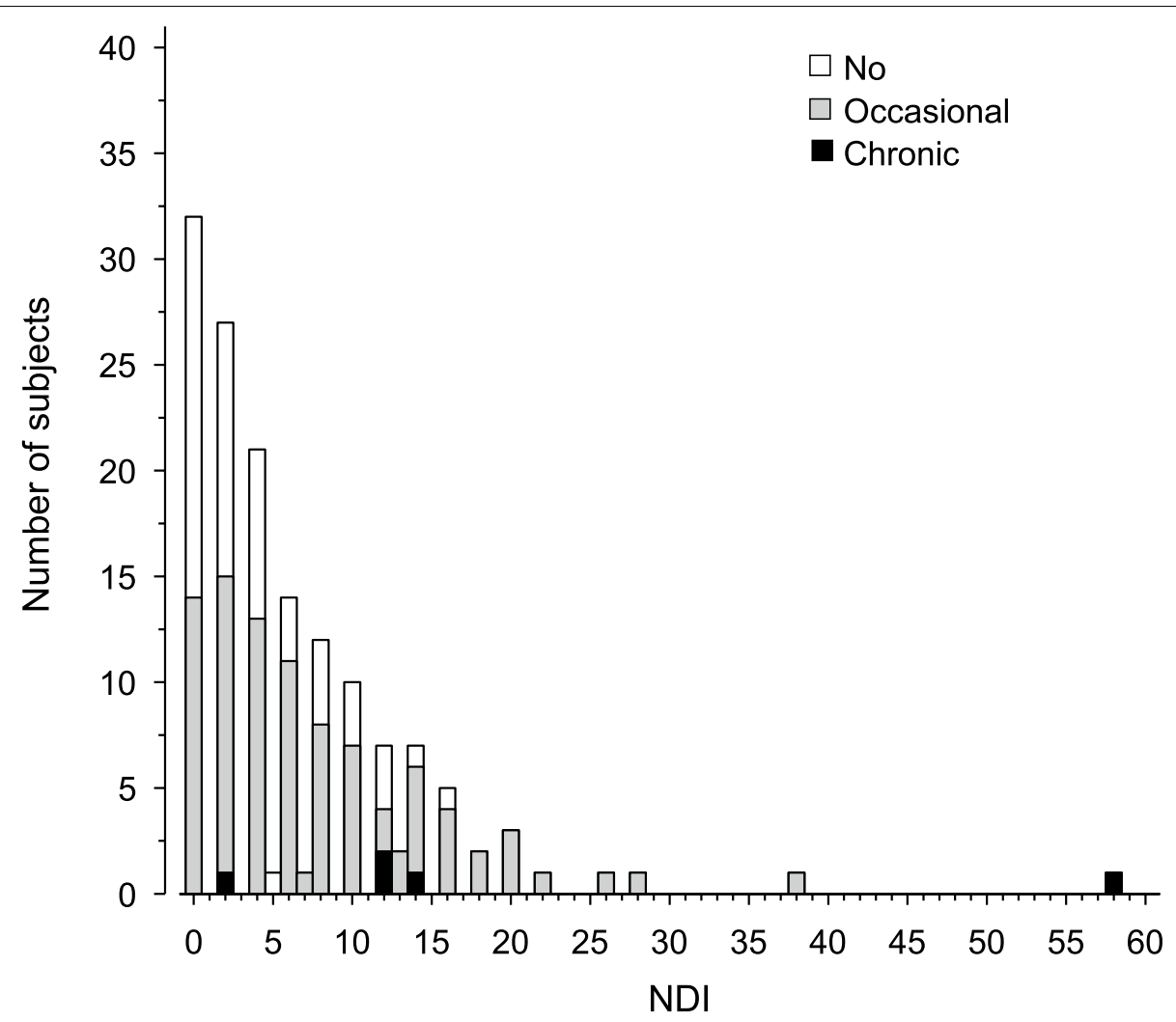

Fig. 1 Distribution of neck disability indices in females who reported no neck pain, occasional neck pain or chronic neck pain during the 16-year follow-up

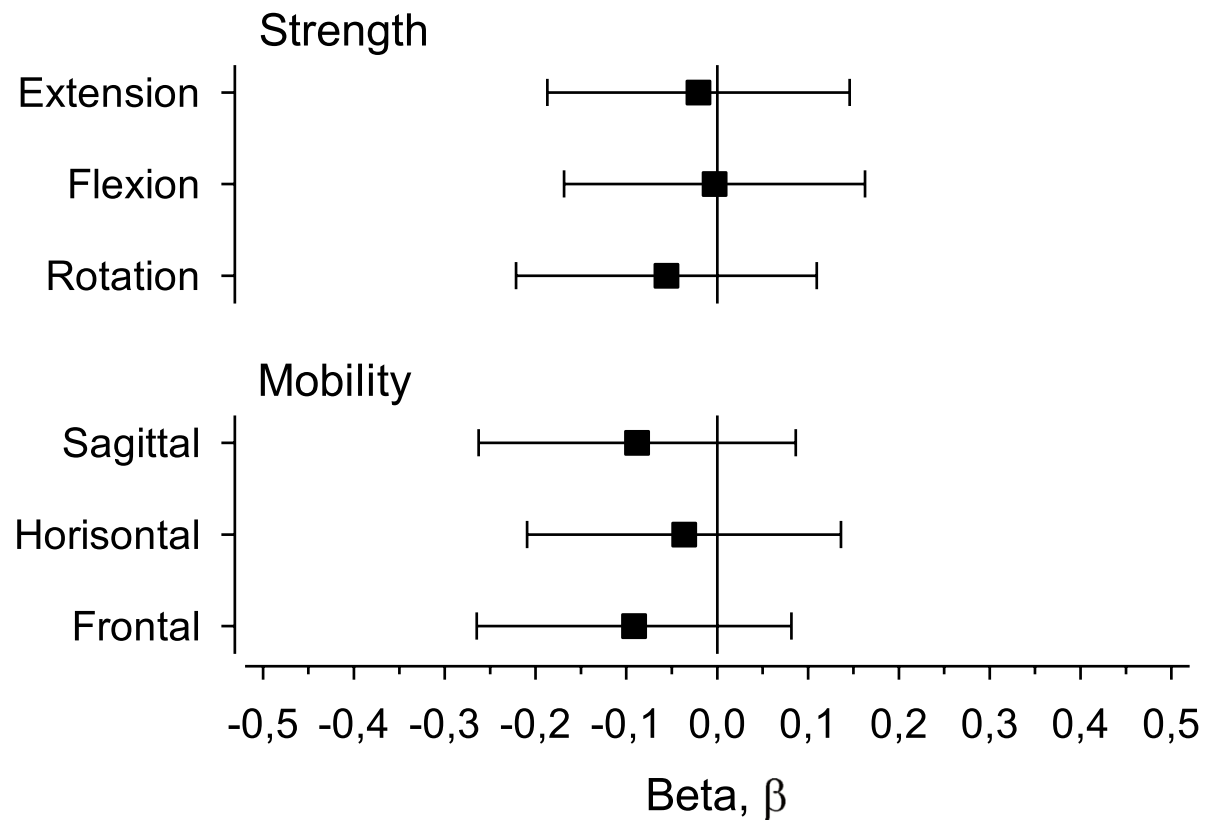

Fig. 2 Association between Neck Disability Index (NDI) and neck muscle strength and cervical spine mobility using adjusted (age and body mass index) standardized regression coefficients ( $\beta$ ). The NDI is plotted on the $x$-axis as $\beta$ values with $95 \%$ confidence intervals 


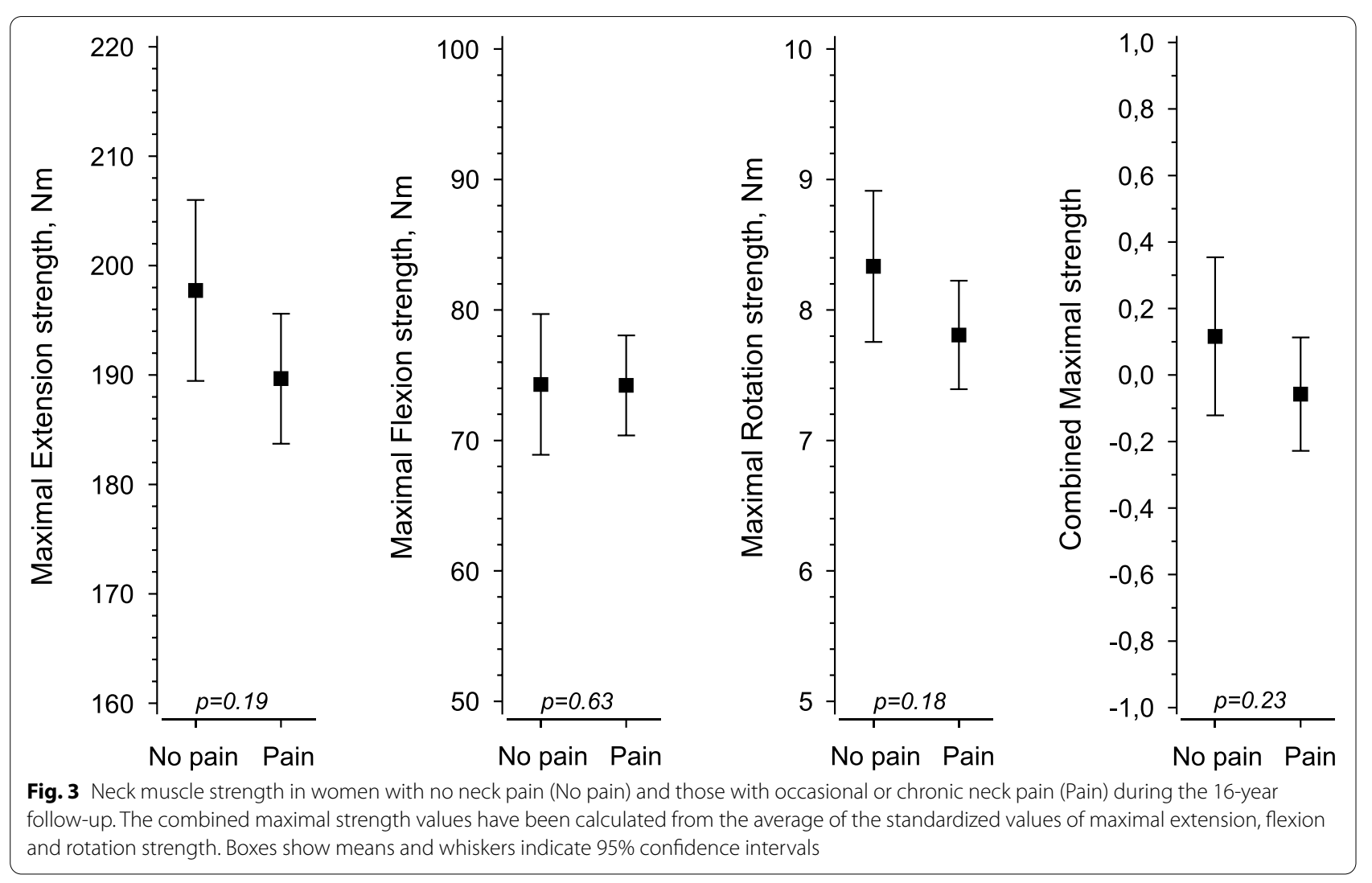

( $p=0.23$ ) (age-adjusted $p$ values, Fig. 3). The strength values of the Chronic group did not differ from those of the No pain ( $p=0.40$ to 0.59$)$ or Occasional groups $(p=0.61$ to 0.99 ).

The mean $(95 \% \mathrm{CI})$ range of motion for passive mobility of the cervical spine in the sagittal plane, frontal plane, and horizontal plane was 167 (162 to 172$)^{0}, 87$ (83 to $91)^{0}$, and $188(183 \text { to } 193)^{0}$, respectively, in the No pain group and $166(162 \text { to } 170)^{0}, 90(87 \text { to } 93)^{0}$, and 192 (188 to 192$)^{0}$, respectively, in the Pain group (Fig. 4). No statistically significant differences between groups were observed in the sagittal plane $(p=0.18)$, horizontal plane $(p=0.85)$, frontal plane $(p=0.81)$ or combined range of motion $(p=0.71)$ values (age-adjusted $p$ values, Fig. 4$)$. The range of motion values of the Chronic group did not differ from those of the No pain ( $p=0.06$ to 0.29$)$ or Occasional group ( $p=0.21$ to 0.54$)$.

\section{Discussion}

This study explored whether neck muscle isometric strength or cervical spine mobility are associated with future neck disability in working-age women with no neck pain at baseline. As far as we know, this is the first study to investigate the association of neck muscle strength with spine mobility and neck disability using measurements of neck muscle strength and cervical spine mobility recorded as many as 16 years earlier. Thus, this study provides valuable information on the topic. The results indicate that the later occurrence of neck disability is not associated with either neck muscle strength or passive mobility of the cervical spine.

Although chronic neck pain and related disability is a common complaint, only a few studies have investigated the correlations of perceived neck-related disability with different physical capacity measures, including the use of linear regression analysis. Among the few correlation studies with neck-related disability as an outcome, Saavedra-Hernandez et al. [37] found a weak but significant negative correlation $(\mathrm{r}=-0.18, p=0.04)$ between cervical extension range of motion and disability in patients with chronic neck pain. Rudolfsson et al. [38], in turn, found that extension in the upper cervical levels and flexion in the lower levels were reduced in people with chronic neck pain. In addition, many studies with chronic neck pain as an outcome have reported that patients with chronic neck pain present reduced cervical range of motion [21, 24, 39, 40] and weaker maximal isometric strength of neck muscles compared to healthy controls $[11-15,39]$. Lower neck muscle strength may be due to inhibition of maximal muscle contraction caused by pain. 


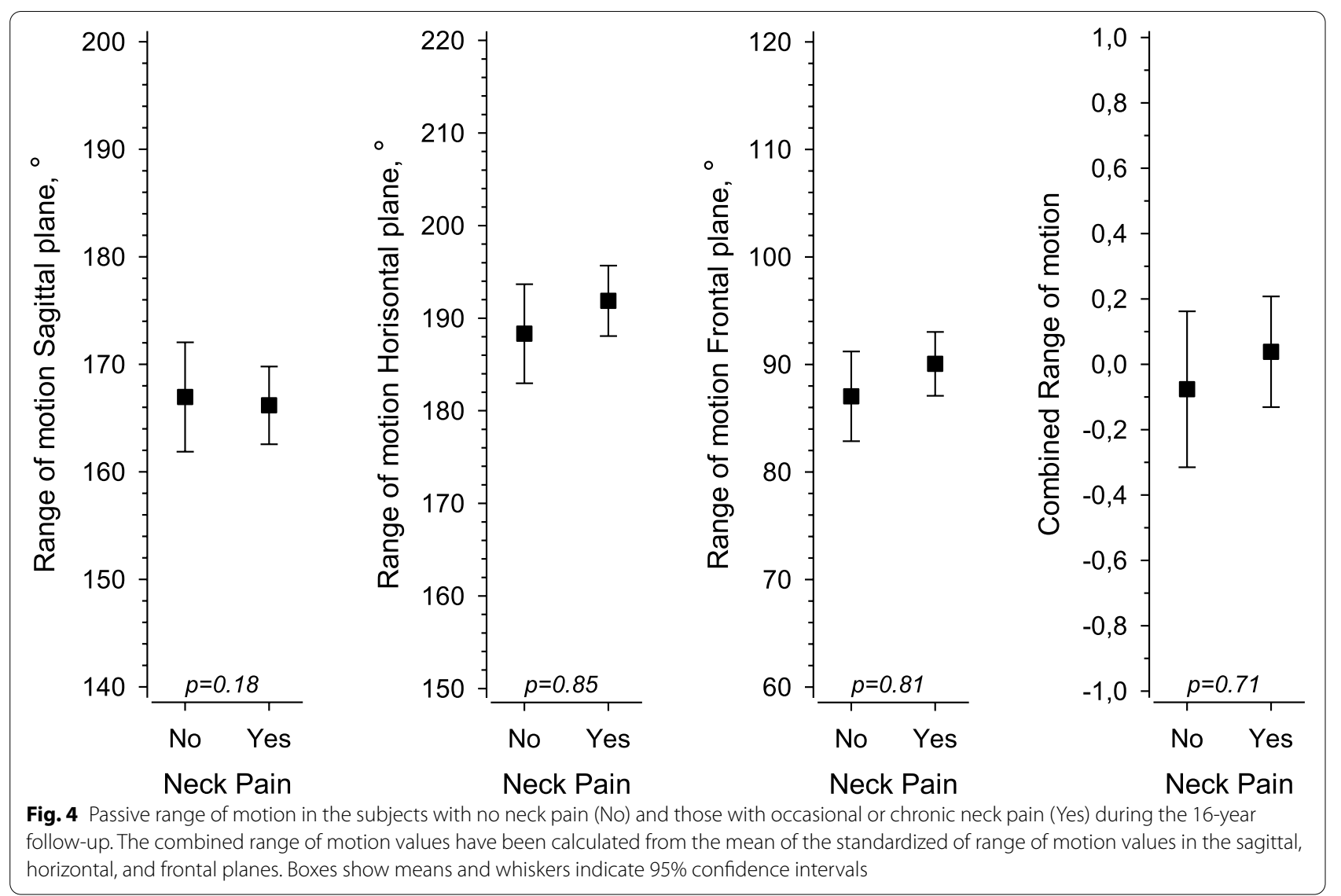

However, it should be noted that the above-mentioned studies observed the relationship at the same time point in time, whereas we investigated the relationship many years later. To our knowledge, very few studies have looked at the association between muscle strength and/ or mobility and future pain/disability in the neck region after a lengthy period of time. Timpka et al. [41], in a large cohort study with a 17-year follow-up, found that low overall isometric muscle strength in youth was not associated with the development of musculoskeletal pain in adulthood in the neck/shoulders, back/hips or arms/ legs. According to the systematic review by Hamberg-van Reenen et al. [42], similar results have been reported for other regions of the body, implying that no association exists between trunk muscle strength, muscle endurance or mobility of the lumbar spine and the risk of future low back pain.

In an earlier study on 192 women from the same study population, the occurrence of neck pain after 6 years was not predicted by either neck muscle strength or cervical spine passive mobility [27]. However, in that study we did not ask about the occurrence of chronic neck pain or use the NDI as an outcome measure. The participants were only asked whether they had experienced neck pain since the baseline measurements 6 years earlier and how many days in total they had experienced neck pain during the preceding 12 months. In the present study, the prevalence of chronic neck pain was $3 \%$, which is somewhat lower than the approximately $5 \%$ previously reported globally $[6,7,29]$. Moreover, the neck disability index in most of these subjects was low. This is due to the study design, as the subjects were initially healthy adults with no history of neck pain.

Given our present findings and the previous literature it would seem plausible that factors other than cervical mobility and muscle strength predict neck disability. Sihawong et al. [43], in a one-year prospective cohort study in office workers, found that frequent neck extension during the workday and a high body mass index predicted chronic neck pain. Further, they found that high initial pain intensity and high psychological job demands were also predictors of chronic neck pain. In another one-year prospective study in office workers, Jun et al. [44] found that older age, increased sedentary hours, higher job strain, and stress were risk factors for the development of neck pain. Furthermore, physical factors, such as impaired in neck muscle endurance [39] and imbalance in sagittal alignment [45], female gender 
[46] and comorbidities [47, 48], have been reported to be important predictors of neck disability. Crosssectional studies, in turn, indicate that psychosocial factors such as depression, anxiety, and catastrophization may be predisposing factors for the development of chronic neck pain, as defined by the Neck Disability Index [49-51]. One predisposing factor alone, however, does not necessarily lead to chronic neck pain. Instead, a combination of predisposing factors needs to be present to trigger neck pain, and such combinations most likely vary between individuals [47].

The strengths of this study are the length of the followup and low drop-out rate. The study also has its limitations. The study population in the chronic group was too small to permit analysis of whether neck strength and mobility are associated with the development of chronic neck pain. Moreover, the age range of the participants varied by 40 years, which could put them in different risk categories for several health-related reasons. However, this confounding factor was to some extent overcome by using an age-adjusted regression model. In addition, we had no information on whether the present participants exercised regularly following the baseline measurements, and if so, whether this was associated with any prevalence of neck pain 16 years later. Lastly, we do not know whether these results apply to aging populations. Some studies suggest that neck strength declines with age [52, 53] and that this decline is associated with neck pain [11-16]. Thus, to investigate this study topic thoroughly, further prospective longitudinal research with a larger cohort of healthy adults across the age spectrum and a variety of confounding factors in addition to neck muscle strength and mobility is required.

\section{Conclusion}

This study found no evidence that isometric neck muscle strength or passive mobility of the cervical spine are associated with the later occurrence of neck pain or disability among originally pain-free women. Therefore, screening healthy subjects for weaker neck muscle strength or poorer cervical spine mobility alone cannot be recommended for preventive purposes. In addition to these physical capacity measures, future follow-up surveys should also include other long-term predictors such as psychosocial and work-related physical risk factors to predict neck pain and related disability.

\footnotetext{
Abbreviations

CMS: Cervical measurement system; Cl: Confidence interval; IASP: The International Association for the Study of Pain; ICC: Intraclass correlation coefficient; NDI: Neck Disability Index; NSMS: Neck strength measurement system; PROM: Passive range of motion; SD: Standard deviation; VAS: Visual analogue scale.
}

\section{Acknowledgements}

The authors express their gratitude to physiotherapists Jonna Hulkkonen and Maiju Hänninen for their help with the data collection.

\section{Authors' contributions}

Coordination of study conduction JM. Study design JM, AH, JY. Data collection JM. Statistical analysis HK. Data interpretation JM, HK, JY. Clinical consultant AH, JY. Manuscript preparation JM. Critical review of the manuscript JM, AJ, JY. Approval of the final draft JM, HK, AH, JY. The author(s) read and approved the final manuscript.

\section{Funding}

Juhani Multanen was funded by the Academy of Finland (grant number 311587) and the Research Committee of the Kuopio University Hospital Catchment Area for State Research Funding when preparing the manuscript for publication. The funding agencies had no role in the study design, data collection and analysis, decision to publish, or preparation of the manuscript.

\section{Availability of data and materials}

The datasets generated and analyzed during the current study are available from the corresponding author on reasonable request.

\section{Declarations}

\section{Ethics approval and consent to participate}

The study protocol followed the guidelines of the Declaration of Helsinki and was approved by the Ethics Committee of the Central Finland Health Care District (protocol approval number 41/2000). Written informed consent was obtained from all participants.

\section{Consent for publication \\ Not applicable.}

\section{Competing interests \\ The author declare that they have no competing interests.}

\section{Author details}

${ }^{1}$ Faculty of Sport and Health Sciences, University of Jyväskylä, Jyväskylä, Finland. ${ }^{2}$ Department of Physical Medicine and Rehabilitation, Central Finland Hospital, Jyväskylä, Finland. ${ }^{3}$ Department of General Practice and Primary Health Care, University of Helsinki, Helsinki, Finland. ${ }^{4}$ Unit of Primary Health Care, Kuopio University Hospital, Kuopio, Finland.

Received: 30 May 2021 Accepted: 12 October 2021

Published online: 29 October 2021

\section{References}

1. Cote P, Cassidy JD, Carroll L. The factors associated with neck pain and its related disability in the Saskatchewan population. Spine (Phila Pa 1976). 2000;25(9):1109-17.

2. Staudte HW, Duhr N. Age- and sex-dependent force-related function of the cervical spine. Eur Spine J. 1994;3(3):155-61.

3. Metter EJ, Lynch N, Conwit R, Lindle R, Tobin J, Hurley B. Muscle quality and age: cross-sectional and longitudinal comparisons. J Gerontol A Biol Sci Med Sci. 1999:54(5):B207-18.

4. Hogg-Johnson S, van der Velde G, Carroll LJ, Holm LW, Cassidy JD, Guzman J, et al. The burden and determinants of neck pain in the general population: results of the Bone and Joint Decade 2000-2010 Task Force on Neck Pain and Its Associated Disorders. Spine (Phila Pa 1976). 2008;33(4 Suppl):S39-51.

5. Fejer R, Leboeuf-Yde C. Does back and neck pain become more common as you get older? A systematic literature review. Chiropr Man Therap. 2012;20(1):24. https://doi.org/10.1186/2045-709X-20-24.

6. Murray CJ, Atkinson C, Bhalla K, Birbeck G, Burstein R, Chou D, et al. The state of US health, 1990-2010: burden of diseases, injuries, and risk factors. JAMA. 2013;310(6):591-608. 
7. Hoy D, March L, Woolf A, Blyth F, Brooks P, Smith E, et al. The global burden of neck pain: estimates from the global burden of disease 2010 study. Ann Rheum Dis. 2014;73(7):1309-15.

8. Anonymous. Classification of chronic pain. Descriptions of chronic pain syndromes and definitions of pain terms. Prepared by the International Association for the Study of Pain, Subcommittee on Taxonomy. Pain Suppl. 1986;3:S1-226.

9. Cohen SP, Hooten WM. Advances in the diagnosis and management of neck pain. BMJ. 2017;358:j3221.

10. Kim R, Wiest C, Clark K, Cook C, Horn M. Identifying risk factors for first-episode neck pain: a systematic review. Musculoskelet Sci Pract. 2018;33:77-83.

11. Chiu TT, Sing KL. Evaluation of cervical range of motion and isometric neck muscle strength: reliability and validity. Clin Rehabil. 2002;16(8):851-8.

12. Ylinen J, Salo P, Nykänen M, Kautiainen H, Häkkinen A. Decreased isometric neck strength in women with chronic neck pain and the repeatability of neck strength measurements. Arch Phys Med Rehabil. 2004;85(8):1303-8.

13. Ylinen J, Takala EP, Kautiainen $H$, Nykänen $M$, Häkkinen $A$, Pohjolainen $T$, et al. Association of neck pain, disability and neck pain during maximal effort with neck muscle strength and range of movement in women with chronic non-specific neck pain. Eur J Pain. 2004;8(5):473-8.

14. Sjøgaard G, Søgaard K, Hermens HJ, Sandsjö L, Läubli T, Thorn S, et al. Neuromuscular assessment in elderly workers with and without work related shoulder/neck trouble: the NEW-study design and physiological findings. Eur J Appl Physiol. 2006;96(2):110-21.

15. Andersen LL, Holtermann A, Jørgensen MB, Sjøgaard G. Rapid muscle activation and force capacity in conditions of chronic musculoskeletal pain. Clin Biomech (Bristol, Avon). 2008;23(10):1237-42.

16. Andersen LL, Nielsen PK, Søgaard K, Andersen CH, Skotte J, Sjøgaard G. Torque-EMG-velocity relationship in female workers with chronic neck muscle pain. J Biomech. 2008;41(9):2029-35.

17. Ahlgren C, Waling K, Kadi F, Djupsjöbacka M, Thornell LE, Sundelin G Effects on physical performance and pain from three dynamic training programs for women with work-related trapezius myalgia. J Rehabil Med. 2001;33(4):162-9

18. Ylinen J, Takala EP, Nykänen M, Häkkinen A, Mälkiä E, Pohjolainen T, et al. Active neck muscle training in the treatment of chronic neck pain in women: a randomized controlled trial. JAMA. 2003;289(19):2509-16.

19. Andersen LL, Kjaer M, Søgaard K, Hansen L, Kryger Al, Sjøgaard G. Effect of two contrasting types of physical exercise on chronic neck muscle pain. Arthritis Rheum. 2008;59(1):84-91.

20. Andersen LL, Andersen CH, Skotte JH, Suetta C, Søgaard K, Saltin B, et al. High-intensity strength training improves function of chronically painful muscles: case-control and RCT studies. Biomed Res Int. 2014;2014:187324.

21. Ylinen JJ, Savolainen S, Airaksinen O, Kautiainen H, Salo P, Häkkinen A. Decreased strength and mobility in patients after anterior cervical diskectomy compared with healthy subjects. Arch Phys Med Rehabil. 2003;84(7):1043-7.

22. Lee $H$, Nicholson LL, Adams RD. Cervical range of motion associations with subclinical neck pain. Spine (Phila Pa 1976). 2004;29(1):33-40.

23. De Loose V, Van den Oord M, Burnotte F, Van Tiggelen D, Stevens V, Cagnie $B$, et al. Functional assessment of the cervical spine in F-16 pilots with and without neck pain. Aviat Space Environ Med. 2009;80(5):477-81.

24. Stenneberg MS, Rood M, de Bie R, Schmitt MA, Cattrysse E, ScholtenPeeters GG. To what degree does active cervical range of motion differ between patients with neck pain, patients with whiplash, and those without neck pain? A systematic review and Meta-analysis. Arch Phys Med Rehabil. 2017;98(7):1407-34.

25. Bronfort G, Evans R, Nelson B, Aker PD, Goldsmith $\mathrm{CH}$, Vernon H. A randomized clinical trial of exercise and spinal manipulation for patients with chronic neck pain. Spine (Phila Pa 1976). 2001;26(7):788-97 discussion 798-9.

26. Hamberg-van Reenen HH, Ariens GA, Blatter BM, Twisk JW, van Mechelen W, Bongers PM. Physical capacity in relation to low back, neck, or shoulder pain in a working population. Occup Environ Med. 2006;63(6):371-7.

27. Salo $P$, Ylinen J, Kautiainen H, Häkkinen $K$, Häkkinen A. Neck muscle strength and mobility of the cervical spine as predictors of neck pain: a prospective 6-year study. Spine (Phila Pa 1976). 2012;37(12):1036-40.
28. MacDermid JC, Walton DM, Avery S, Blanchard A, Etruw E, McAlpine C, et al. Measurement properties of the neck disability index: a systematic review. J Orthop Sports Phys Ther. 2009;39(5):400-17.

29. Aromaa A, Koskinen S. Health and functional capacity in Finland: Baseline results of the Health 2000 health examination survey. B12/2004.

30. Salo PK, Ylinen JJ, Mälkiä EA, Kautiainen H, Häkkinen AH. Isometric strength of the cervical flexor, extensor, and rotator muscles in 220 healthy females aged 20 to 59 years. J Orthop Sports Phys Ther. 2006;36(7):495-502.

31. Salo PK, Häkkinen AH, Kautiainen $H$, Ylinen JJ. Quantifying the effect of age on passive range of motion of the cervical spine in healthy working-age women. J Orthop Sports Phys Ther. 2009;39(6):478-83.

32. Salo $P$, Ylinen J, Kautiainen $H$, Arkela-Kautiainen M, Häkkinen A. Reliability and validity of the finnish version of the neck disability index and the modified neck pain and disability scale. Spine (Phila Pa 1976). 2010;35(5):552-6.

33. Vernon $\mathrm{H}$, Mior $\mathrm{S}$. The neck disability index: a study of reliability and validity. J Manip Physiol Ther. 1991;14(7):409-15.

34. Fairbank JC, Couper J, Davies JB, O'Brien JP. The Oswestry low back pain disability questionnaire. Physiotherapy. 1980;66(8):271-3.

35. Vernon $\mathrm{H}$. The neck disability index: state-of-the-art, 1991-2008. J Manip Physiol Ther. 2008;31(7):491-502.

36. Cohen J. Statistical power analysis for the behavioral sciences. 2 nd ed. Hillsdale: Lawrence Erlbaum; 1988.

37. Saavedra-Hernandez M, Castro-Sanchez AM, Cuesta-Vargas Al, Cleland JA, Fernandez-de-las-Penas C, Arroyo-Morales M. The contribution of previous episodes of pain, pain intensity, physical impairment, and pain-related fear to disability in patients with chronic mechanical neck pain. Am J Phys Med Rehabil. 2012;91(12):1070-6.

38. Rudolfsson T, Björklund M, Djupsjöbacka M. Range of motion in the upper and lower cervical spine in people with chronic neck pain. Man Ther. 2012;17(1):53-9.

39. Dimitriadis Z, Kapreli E, Strimpakos N, Oldham J. Hypocapnia in patients with chronic neck pain: association with pain, muscle function, and psychologic states. Am J Phys Med Rehabil. 2013;92(9):746-54.

40. Woodhouse A, Vasseljen O. Altered motor control patterns in whiplash and chronic neck pain. BMC Musculoskelet Disord. 2008;9:90. https:// doi.org/10.1186/1471-2474-9-90.

41. Timpka S, Petersson IF, Zhou C, Englund M. Muscle strength in adolescent men and future musculoskeletal pain: a cohort study with 17 years of follow-up. BMJ Open. 2013;3(5):e002656. https://doi.org/10. 1136/bmjopen-2013-002656.

42. Hamberg-van Reenen HH, Ariëns GA, Blatter BM, van Mechelen W, Bongers PM. A systematic review of the relation between physical capacity and future low back and neck/shoulder pain. Pain. 2007;130(1-2):93-107.

43. Sihawong R, Sitthipornvorakul E, Paksaichol A, Janwantanakul P. Predictors for chronic neck and low back pain in office workers: a 1-year prospective cohort study. J Occup Health. 2016;58(1):16-24.

44. Jun $\mathrm{D}$, Johnston $\mathrm{V}, \mathrm{McPh}$ ail SM, O'Leary S. A longitudinal evaluation of risk factors and interactions for the development of nonspecific neck pain in office workers in two cultures. Hum Factors. 2021;63(4):663-83.

45. Iyer S, Nemani VM, Nguyen J, Elysee J, Burapachaisri A, Ames CP, et al. Impact of cervical sagittal alignment parameters on neck disability. Spine (Phila Pa 1976). 2016;41(5):371-7.

46. Webb R, Brammah T, Lunt M, Urwin M, Allison T, Symmons D. Prevalence and predictors of intense, chronic, and disabling neck and back pain in the UK general population. Spine (Phila Pa 1976). 2003;28(11):1195-202.

47. Cote P, van der Velde G, Cassidy JD, Carroll LJ, Hogg-Johnson S, Holm LW, et al. The burden and determinants of neck pain in workers: results of the Bone and Joint Decade 2000-2010 Task Force on Neck Pain and Its Associated Disorders. Spine (Phila Pa 1976). 2008;33(4 Suppl):S60-74.

48. Uddin Z, MacDermid JC, Woodhouse LJ, Triano JJ, Galea V, Gross AR. The effect of pressure pain sensitivity and patient factors on self-reported pain-disability in patients with chronic neck pain. Open Orthop J. 2014;8:302-9.

49. Mäntyselkä P, Lupsakko T, Kautiainen H, Vanhala M. Neck-shoulder pain and depressive symptoms: a cohort study with a 7-year follow-up. Eur J Pain. 2010;14(2):189-93. 
50. Shahidi B, Curran-Everett D, Maluf KS. Psychosocial, physical, and neurophysiological risk factors for chronic neck pain: a prospective inception cohort study. J Pain. 2015;16(12):1288-99.

51. Viana MC, Lim CCW, Garcia Pereira F, Aguilar-Gaxiola S, Alonso J, Bruffaerts $R$, et al. Previous mental disorders and subsequent onset of chronic Back or neck pain: findings from 19 countries. J Pain. 2018;19(1):99-110.

52. Peolsson A, Oberg B, Hedlund R. Intra- and inter-tester reliability and reference values for isometric neck strength. Physiother Res Int. 2001;6(1):15-26.
53. Garces GL, Medina D, Milutinovic L, Garavote P, Guerado E. Normative database of isometric cervical strength in a healthy population. Med SC Sports Exerc. 2002:34(3):464-70.

\section{Publisher's Note}

Springer Nature remains neutral with regard to jurisdictional claims in published maps and institutional affiliations.
Ready to submit your research? Choose BMC and benefit from:

- fast, convenient online submission

- thorough peer review by experienced researchers in your field

- rapid publication on acceptance

- support for research data, including large and complex data types

- gold Open Access which fosters wider collaboration and increased citations

- maximum visibility for your research: over $100 \mathrm{M}$ website views per year

At BMC, research is always in progress.

Learn more biomedcentral.com/submissions 